\title{
A capacity-building conceptual framework for public health nutrition practice
}

\author{
Elizabeth Baillie ${ }^{1}$, Christel Bjarnholt ${ }^{2}$, Marlies Gruber ${ }^{3}$ and Roger Hughes ${ }^{1, *}$ \\ ${ }^{1}$ School of Health and Sports Sciences, University of the Sunshine Coast, Maroochydore, 4558 Queensland, \\ Australia: ${ }^{2}$ Unit for Public Health Nutrition, Karolinska Institutet, Stockholm, Sweden: ${ }^{3}$ Forum.ernaehrung heute, \\ Vienna, Austria
}

Submitted 17 September 2007: Accepted 3 April 2008: First published online 22 October 2008

\begin{abstract}
Objectives: To describe a conceptual framework to assist in the application of capacity-building principles to public health nutrition practice.

Design: A review of the literature and consideration of the determinants of effective public health nutrition practice has been used to inform the development of a conceptual framework for capacity building in the context of public health nutrition practice.

Result: The limited literature supports a greater integration and application of capacity-building strategies and principles in public health nutrition practice, and that this application should be overt and strategic. A framework is proposed that identifies a number of determinants of capacity for effective public health nutrition action. The framework represents the key foundations for building capacity including leadership, resourcing and intelligence. Five key strategic domains supported by these foundation elements, including partnerships, organisational development, project management quality, workforce development and community development, are proposed. This framework can be used to assist the systematic assessment, development and evaluation of capacity-building activity within public health nutrition practice.

Conclusions: Capacity building is a strategy within public health nutrition practice that needs to be central to public health nutrition intervention management. The present paper defines, contextualises and outlines a framework for integrating and making explicit the importance of capacity building within public health nutrition practice at many levels.
\end{abstract}

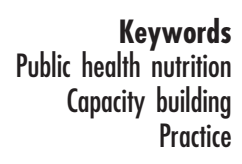

Despite the development of public health nutrition (PHN) as a field of practice over the past few decades, little has been published to support an assessment of or describe what constitutes capacity building in PHN practice. A number of studies have attempted to describe self-reports of practice as part of workforce development research ${ }^{(1,2)}$ and others have attempted to articulate the competency requirements for PHN practice that logically reflect the work required for effective practice ${ }^{(3,4)}$. A consistent finding from the present work has been practice-based activity that reflects a process of development, implementation and evaluation of population-level interventions as a core function and practice focus for public health nutritionists ${ }^{(5)}$, and an appreciation of the importance of building capacity to support action to address PHN issues. Each of these broad areas of practice is consistent across health promotion and broader public health effort. Consideration of capacity building as a practice concept (what, why and how?) for PHN therefore is needed.
The present paper draws on a non-exhaustive review of scholarship in the published and grey literature from the disciplines of nutrition, public health and health promotion. This has been considered against the experience of the authors in practice to propose a conceptual framework for the application of capacity-building principles to PHN practice. This review has enabled a summary of definitions, attributes and relevance of capacity building in the context of PHN practice. We propose that capacity building should be considered a central strategy in PHN practice, important in all stages of the intervention planning cycle and relevant to practice at all levels. The position taken throughout the rest of this paper is that capacity building should be discussed, described and evaluated in the same way as we describe other strategic approaches to public health action. In fact, it is so relevant to effective PHN action that it needs to be considered in parallel with the accepted programme planning processes and methods, so that it is central to practice and strategic deliberations about public health action. 
This approach follows that proposed previously by Labonte et $a l^{(6)}$.

\section{Design}

A review of the relevant literature was conducted to inform the development of a conceptual framework to describe capacity building in PHN practice, assisted by the observations and experiences of the authors in practice. The purpose of the literature review was to search for definitions of capacity building and other relevant capacity-related terms, and to investigate the use of capacity-building strategies in PHN practice. Searches of the peer-reviewed and grey literature were performed. Keyword searches in electronic journal databases such as PubMed, CINHAL and the Health Reference Centre and the Internet search engine Google were conducted. A dual-staged search approach was adopted. The first stage involved using common capacity-related search terms such as 'capacity', 'capacity building', 'community capacity' and 'capacity development'. Search terms used in the second stage were informed by the literature found in the first stage of searching, and included a number of other more detailed capacity-related terms such as workforce development, partnerships, governance, communication, infrastructure and leadership.

\section{Defining capacity building}

Capacity, capacity development and capacity building have been terms that have increasingly become part of the public health vernacular since the Jakarta statement on health promotion ${ }^{(7)}$. This is particularly true of PHN activity in the developing world through agencies such as the United Nations Standing Committee on Nutrition ${ }^{(8,9)}$ and the $\mathrm{FAO}^{(10)}$. These terms were borrowed originally from applications in the fields of agricultural research and development (with an emphasis on training) and management (with an emphasis on organisational development). Capacity building in this context involves the protection and development of human, social, physical and natural capital. These terms are now part of the jargon of health promotion with variable use and meanings applied to these terms ${ }^{(11-14)}$. A number of different capacity definitions used in the public health literature have been summarised in Table 1, with the key attributes of each definition highlighted in bold text.

Capacity, most simply defined, is the ability to carry out stated objectives ${ }^{(15)}$. In the context of PHN practice, it relates to the ability at various levels (individuals, groups, organisations, workforce, systems, state, ecosystem) to perform effectively, efficiently and in a sustainable manner in order to achieve objectives such as improved health ${ }^{(16)}$. This is also particularly relevant to PHN practice in developed economies. We argue therefore that PHN practice in the developed economies of the world has much to gain in terms of effectiveness, by drawing on the approaches to capacity building in practice that have developed from work in the developing countries.

Many of the core functions of public health practice articulated in different national core functions statements ${ }^{(17-19)}$ relate to capacity building, emphasising the importance of this activity in PHN practice. This is reflected also in the specific reference to capacity-building strategies (such as workforce development, research and partnership development) in some (but certainly not all) national PHN strategy plans ${ }^{(20-22)}$. Using Australia as an example, the national PHN strategy (Eat Well Australia) explicitly prioritises capacity building as a strategy imperative that includes workforce development, research and development, monitoring and surveillance and communication.

There are multiple uses for the term capacity building and, as such, reducing this complex term into a single precise definition would be too limiting. It is however important for public health nutritionists to understand the various attributes of capacity in order to prevent potential misinterpretation, misuse and confusion. A common understanding of the term relevant to PHN may also

Table 1 Various definitional attributes of capacity building

- The cultivation and use of transferable knowledge, skill, systems and resources that affect community and individual level changes consistent with public health-related goals and objectives ${ }^{(15)}$.

- System-wide increases in capacity to meet stated objectives whether through increased skills, improvements in information flow or through increases in resource acquisition ${ }^{(25)}$.

- An ongoing process by which individuals, groups, organisations and societies increase their abilities to perform core functions, solve problems, define and achieve objectives, and understand and deal with their development needs in a broad context and sustainable manner ${ }^{(16)}$.

- A continual process of improvement within an individual, organisation or institution with the objective of maintaining or improving the health services being provided ${ }^{(20)}$.

- The process by which people gain knowledge, skills and confidence to improve their own lives ${ }^{(47)}$.

- As enhancement of the skills of people and the capacity of institutions in resources management through education and training ${ }^{(48)}$

- Building is an approach to development based on equity, empowerment, and participation and works to strengthen communities, whether grassroots, inter-organisational partnerships, or networks of agencies, to organise and act to achieve their goals ${ }^{(49)}$.

- Capacity building is an approach to the development of sustainable skills, structures, resources and commitment to health improvement in health and other sectors to prolong and multiply health gains. It increases the range of people, organisations and communities who are able to address health problems (e.g. obesity), and in particular, problems that arise out of social inequity and social exclusion ${ }^{(50)}$. 
encourage more effective integration of capacity-building principles into daily practice.

\section{A need to bring capacity building to the forefront of public health nutrition practice}

Capacity building has been referred to as the invisible work of health promotion because it is often done behind the scenes, rather than as a specific and overt strategy. The invisibility of capacity building has been described by Hawe $^{(11)}$ as having been needed for a number of reasons. Firstly, to ensure others would gain the credit for project success (and thus projects would be more likely to be sustained by these other parties). In work with sectors outside of health, Hawe's work suggests that practitioners perceive a need to work invisibly because confronting another person or organisation with an agenda about health promotion in the first instance is unlikely to set the right conditions for collaboration. Another reason suggested by Hawe ${ }^{(13)}$ is that discourse about capacity building is hidden from funders and administrators because the official purposes of most programmes are health priority areas and the only 'legitimate' activities were perceived to be those directed specifically to risk factor change among population groups. This suggests a failure among practitioners and resource allocators to recognise the importance and potential of capacity-building activities to be a cost-efficient and value-adding approach to practice. We contend therefore that capacity-building strategies and evaluation in practice should be made visible, communicated, debated and recognised by practitioners and resource allocators as important and legitimate strategies.

\section{The attributes of capacity building in practice}

A number of attributes of capacity building in practice need to be described to provide a context for the following framework.

\section{A continual process}

Capacity-building definitions often refer to the ongoing or continuous nature of this activity. Capacity building in theory is an indefinite process, which can go on continuously because of the ever-changing conditions of community issues, forcing practitioners and organisations to constantly identify and meet new challenges. Therefore, there cannot be a single product or output of capacity building. Capacity building should not be perceived as a 'project' that is finished once project activities come to an end ${ }^{(6,23)}$, but as a central component of PHN process and planning (refer Fig. 1).

\section{A performance focus}

Common to all characterisations of capacity building is the assumption that capacity is linked to performance (i.e. achieving the goals and objectives relating to improving health and well-being). A need for capacity building is often identified when performance is inadequate or falters and capacity building is only perceived as effective if it contributes to better performance.

Brown et al. ${ }^{(24)}$ suggest that if capacity is defined as 'the ability to carry out stated objectives,' then capacity building is a process that improves the ability of a person, group, organisation or system to meet its objectives or perform better. Capacity-building interventions, therefore, work to improve the processes that go on within the health system as a whole (improvement in function); the organisations within the health system (improvement in function); health personnel (improvement in ability to perform work functions); and individuals (improvement in ability to engage productively with the health system through access to services and influencing resource management, and improving their own health $\left.{ }^{(24)}\right)$. Capacity plays a prominent role in securing health system performance ${ }^{(25)}$. We argue that performance in the PHN discipline area can be enhanced with a more overt and strategic approach to capacity building in practice.

\section{Capacity building and sustainability}

The concept of sustainability is widely used interchangeably with, or in the context of, capacity building. In the health sector, the ultimate goal of 'generalised' capacity building is a sustainable local health system - so, any activity, project or change in environment that improves the ability of a health system to bring about positive health outcomes is considered a capacity-building intervention ${ }^{(16)}$.

It has been argued that sustainable effects may not be the 'last word' on whether or not a public health programme has been truly successful. A better or higher level indicator of programme success may be that the intervention renders the community or the partner organisation more competent, not only to address the health problem of current interest but also to tackle other health issues ${ }^{(26)}$. A programme that shows high health gains but low potential for sustainability may not be as good an investment as a programme with a more modest initial health gain but with a high sustainability potential. A programme that in addition demonstrates that the partner organisation or community is better able to tackle other health issues, and not simply the health issue targeted by the immediate programme, may be an even better choice ${ }^{(26)}$. PHN practitioners therefore need to practice with a vision of a community that becomes selfreliant and no longer in need of specialist support.

\section{Capacity building at numerous levels}

Many of the definitions of capacity building refer to capacity in the context of various levels, such as individual, organisational or system capacity. For example, the capacity of an individual to successfully change 
behaviour may be dependent on their ability to learn, participate in social networks and appreciate risk and benefits. The capacity of an organisation to mount organised efforts to address a problem like obesity (i.e. obesity prevention) may be limited by its organisational goals. For example, a hospital (an organisation) that has its primary objectives to treat the unwell may struggle to effectively mount an obesity prevention campaign.

\section{Capacity building as core to public bealth nutrition practice}

Capacity building occasionally happens as an activity in its own right, but more often is combined with the development and delivery of a public health programme. This is why, in a practice context, it needs to be recognised and disentangled. As practitioners, we need to be conscious of capacity building and its place in our practice. Others have argued that capacity building needs to be considered and planned in parallel with other strategies in the intervention management cycle $^{(\sigma)}$. The capacity-building literature outside public health suggests the process of capacity building should be an interlinked, continuing process that consists of several interrelated elements:

- the assessment of capacity-building needs through a variety of activities using a variety of tools and instruments;

- the planning of a capacity-building programme involving various stakeholders;

- the implementation of the capacity-building programme using own resources or resources provided by others (like the local government); and finally

- the evaluation of the impacts of capacity-building activities. The last step (evaluation) would then again restart the capacity-building cycle $^{(23)}$.

This reflects the standard public health intervention planning cycle common to public health and more latterly to PHN practice ${ }^{(27-29)}$. Figure 1 borrows from these earlier models (in particular the 'Triple A cycle' developed to address the causes of malnutrition, which made explicit the importance of action in the context of capacity) and conceptualises the various stages of this practice cycle with explicit identification of capacity building as a central and inter-linking strategy process.

Table 2 describes the relevance of capacity as a prerequisite for effective $\mathrm{PHN}$ intervention management and how each stage of the intervention management cycle can enhance capacity.

\section{A capacity-building framework for public health nutrition practice}

Figure 2 depicts a conceptual framework that illustrates the relationship between the different domains, or determinants, of capacity building in PHN practice. These capacity determinants provide a focus for assessing,

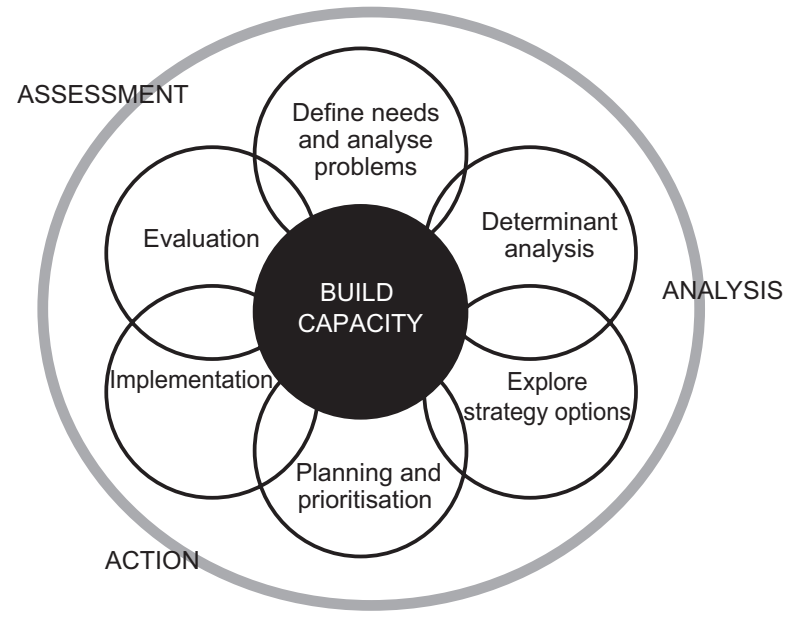

Fig. 1 Public health nutrition intervention management practice cycle

planning, implementing and evaluating capacity-building strategies in practice.

The base of this model represents the key foundations for building capacity including leadership, resourcing and intelligence. Building on these foundation layers are five key strategic domains, including partnerships, organisational development, project management quality, workforce development and community development. In this model, attention to developing each of the determinants of capacity logically contributes to capacity building, and as such brings about general public health and wellbeing. It is no coincidence that each of these capacity domains is clearly identifiable in many of the competency frameworks that have been developed in public health, health promotion and PHN. This clearly demonstrates the relationship between capacity building in practice and practitioner performance.

\section{Leadership}

Leadership is essential to building capacity ${ }^{(30)}$ and is largely about the process of influence ${ }^{(31)}$. Developing leadership across a number of levels of public health action (jurisdictions, sectors, community) increases the degree of influence and improving the likelihood that PHN strategies can be effectively implemented. Building capacity for PHN practice requires the development of leadership across all levels of public health action including political, organisational, community, workforce and project management levels.

\section{Resourcing}

Resources are required to enable action and to support change within communities. In addition to funding (that can be applied to recruiting staff, investing in physical infrastructure, etc.), capacity building also relies on intangible resources such as knowledge and skills of people ${ }^{(15)}$, and in-kind contributions from stakeholders. 
Table 2 Capacity prerequisites and capacity gain at each stage of the PHN intervention management cycle

\begin{tabular}{|c|c|c|c|}
\hline Stage* $^{*}$ & & Suggested capacity prerequisites & Capacity gain examples \\
\hline Assessment & $\begin{array}{l}\text { Define needs and } \\
\text { analyse problems }\end{array}$ & $\begin{array}{l}\text { Need and problem analysis requires access } \\
\text { to information derived from research, } \\
\text { community and stakeholder consultation } \\
\text { and appropriate analytical expertise }\end{array}$ & $\begin{array}{l}\text { The act of consultation, collation of information } \\
\text { and analysis has independent capacity } \\
\text { building effects. Stakeholders and } \\
\text { communities can be empowered through } \\
\text { genuine consultation and community } \\
\text { priorities can be identified }\end{array}$ \\
\hline \multirow[t]{2}{*}{ Analysis } & Determinant analysis & $\begin{array}{l}\text { Isolation and description of the social, } \\
\text { economic, environmental and physical } \\
\text { determinants (causative and protective } \\
\text { factors) of public health problems requires } \\
\text { similar prerequisites as above }\end{array}$ & $\begin{array}{l}\text { Dissemination of determinant analysis } \\
\text { results to stakeholders and communities } \\
\text { can assist shared understanding and } \\
\text { decision making regarding priorities and } \\
\text { strategy options }\end{array}$ \\
\hline & $\begin{array}{l}\text { Explore strategy } \\
\text { options }\end{array}$ & $\begin{array}{l}\text { Access to intervention research findings } \\
\text { (what evidence is there that strategies } \\
\text { have worked before) and practice } \\
\text { wisdomt. Consultation and involvement of } \\
\text { the community and stakeholders about } \\
\text { potential solutions }\end{array}$ & $\begin{array}{l}\text { Shared decision making about strategy } \\
\text { options can empower stakeholders and } \\
\text { encourage later target group engagement in } \\
\text { interventions }\end{array}$ \\
\hline \multirow[t]{2}{*}{ Action } & Planning & $\begin{array}{l}\text { Planning expertise such as familiarity with } \\
\text { logic modelling, project management and } \\
\text { leadership }\end{array}$ & $\begin{array}{l}\text { Participation of stakeholders in planning can } \\
\text { be empowering (as per shared-decision } \\
\text { making). Well-developed plans provide a } \\
\text { structural platform for effective intervention } \\
\text { implementation }\end{array}$ \\
\hline & $\begin{array}{l}\text { Implement the strategy } \\
\text { portfolio }\end{array}$ & $\begin{array}{l}\text { Resources, commitment and engagement } \\
\text { by stakeholders }\end{array}$ & $\begin{array}{l}\text { Implementation (the 'doing phase' of } \\
\text { interventions) can consolidate partnerships, } \\
\text { encourage ongoing consultation and } \\
\text { community development }\end{array}$ \\
\hline Assessment & Evaluation & $\begin{array}{l}\text { Evaluation skills, access to data, target } \\
\text { group consultation and detailed } \\
\text { understanding of the intervention logic and } \\
\text { context. Evaluation should answer the } \\
\text { question of whether the intervention has } \\
\text { achieved goals and objectives and } \\
\text { sustained outcomes and effects }\end{array}$ & $\begin{array}{l}\text { Evaluation and reflection on strategies and } \\
\text { decision making can enhance shared } \\
\text { understanding, build intelligence and share } \\
\text { learning. The experience of implementation } \\
\text { as measured in process evaluation can } \\
\text { support sustainable gains in community } \\
\text { competence in problem-solving }\end{array}$ \\
\hline
\end{tabular}

PHN, public health nutrition.

${ }^{*}$ From Ewles and Simnett ${ }^{(27)}$, Jonsson ${ }^{(28)}$ and Margetts ${ }^{(29)}$.

tPractice wisdom refers to the knowledge and insights gained from experience in practice, based on observation, previous anecdotal or empirical evaluation, and reflective practice.

Sustainable public health outcomes

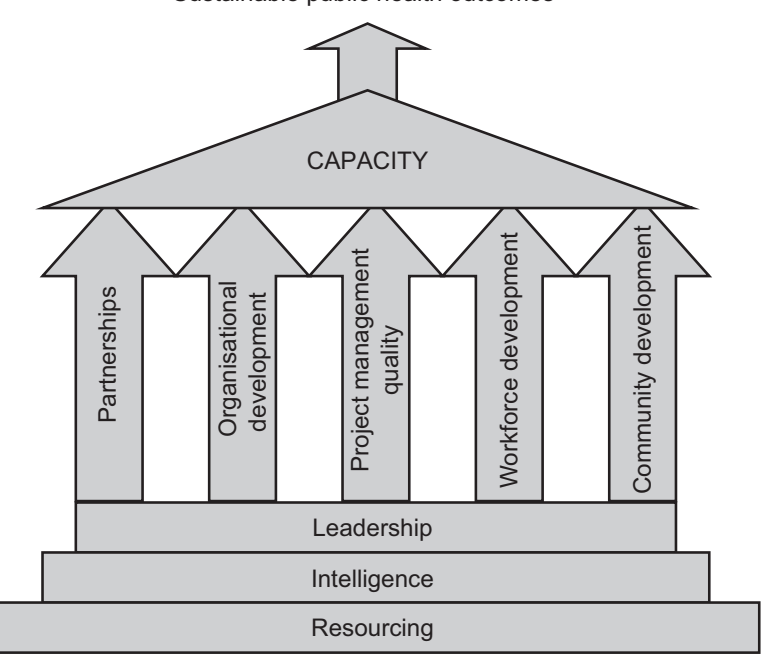

Fig. 2 Capacity-building conceptual framework

Capacity building is enhanced when resources are able to be mobilised and when they are allocated effectively. To build capacity in PHN practice, resources need to be mobilised from within communities as well as from outside funding sources. It is then important to ensure that resources are not solely allocated to the provision of services and PHN programmes, but that equal focus is given to develop human resources, research opportunities and infrastructure.

\section{Intelligence}

Intelligence can be defined as information from various sources that can guide effective and systematic PHN strategy development and problem resolution ${ }^{(32)}$. This term refers to the published literature as well as to the experiences, opinions and knowledge of people working (practice wisdom) in the field. Capacity can be enhanced by using such intelligence sources to inform strategy development. Building capacity in PHN practice requires significant investment in gathering intelligence to inform strategy development. This includes conducting a thorough needs assessment to understand the determinants of the PHN problem and the nature of the target population. To prevent repetition of previous practice mistakes, intelligence needs to be shared between stakeholders and the professional community. Practice wisdom should 
be considered as a valuable resource that can assist decision making.

\section{Community development}

There is growing evidence that capable communities are crucial to the success of community-based interventions ${ }^{(33,34)}$. The Jakarta Declaration states that in order for health promotion actions to be effective, people need to be at the centre of decision-making processes ${ }^{(35)}$. This process involves engaging with communities, increasing their involvement in decisions about health service design and delivery ${ }^{(34,36)}$, and improving their sense of ownership in the programme ${ }^{(37)}$. A key contributor to building capacity in PHN practice is community development. Engaging with the community and encouraging them to identify their PHN problems, then supporting their involvement in strategy identification, strategy planning, implementation and eventual participation are crucial to building capacity in PHN practice.

\section{Partnerships}

Partnerships bring together individuals and organisations to pursue a shared interest. These relationships are often required in order to address the many aspects of different problems. Successful capacity-building partnerships are those that increase the capacity of parties to work together effectively ${ }^{(38)}$. A partnership that contributes to building capacity should comprise a diverse membership with a shared vision, be able to communicate proficiently and readily exchange available resources and skills. PHN problems are often multi-dimensional, requiring a variety of expertise to address the issue. Creating successful partnerships brings a diverse array of skills and resources to $\mathrm{PHN}$ practice.

\section{Organisational development}

Nearly all capacity-building initiatives work in some way with and through organisations ${ }^{(39)}$. The structures, processes and management systems within organisations may influence their contribution to capacity building. Ensuring organisations have mandates and policies in place to support and direct effort towards PHN issues is crucial to building capacity in PHN practice. It is also important that the characteristics of a learning organisation are adopted to provide a clear direction to focus capacitybuilding efforts ${ }^{(26)}$. Characteristics of a learning organisation include an openness to new ideas and a culture that encourages and provides opportunities for learning and innovation. Knowledge of the organisations' goals and mission and an understanding of how each person as part of the organisation contributes are also important ${ }^{(40)}$.

\section{Workforce development}

A key component of the public health infrastructure is workforce capacity and competency ${ }^{(41,42)}$. There is a greater opportunity to build capacity when workforces comprise employees with training or experience specific to the issue, have organisational and management support, have opportunities for professional development, engage with the target community and base their practice on intelligence and intervention research ${ }^{(42)}$. Ensuring that the PHN workforce is of adequate size and is comprised of competent staff is essential to building capacity in PHN practice. The multilevel and multi-disciplinary nature of the work required to be effective in PHN practice also requires workforce development to be a core function of the specialist PHN workforce $^{(5)}$. Up-skilling of health and community workers (e.g. nurses, teachers) and community leaders in nutrition to enhance the reach and effectiveness of community-based nutrition interventions is widely recognised as an important capacity-building strategy in this field ${ }^{(43)}$.

\section{Project management quality}

The quality and effectiveness of project management by practitioners and their partners may determine how well a community intervention achieves its objectives. Project management refers to the planning, organising, directing and controlling of project resources to complete specific goals and objectives ${ }^{(44,45)}$. Adopting quality project management practices improves the capacity to develop effective strategies to deal with the problem or issue. The Preffi $2 \cdot 0$ Effective Management Instrument ${ }^{(46)}$ is an example of the type of standards that have been developed to guide health promotion project management quality and are underpinned by practices consistent with capacity building. Figure 1 identifies project management quality as a determinant of capacity in PHN practice and this is further de-constructed and described in Table 2.

\section{Conclusions}

Capacity building needs to be acknowledged as a central health promotion strategy in itself as well as a philosophical approach to PHN practice. Capacity building is a continual process that acts in parallel at each point along the public health intervention planning cycle. The present paper has presented a conceptual framework for capacity building in PHN interventions, which has outlined a number of determinants of capacity to focus on capacity-building efforts that are critical for effective PHN action. This capacity-building conceptual framework can be used to assist the systematic assessment, development and evaluation of capacity-building activity within $\mathrm{PHN}$ practice.

\section{Acknowledgements}

Source of funding: This was an unfunded study.

Conflict of interest: There is no known conflict of interest.

Authorship responsibilites: R.H., E.B, C.B. and M.G. each contributed to the literature review, collectively 
assisted the conceptualisation of the framework and the drafting and final editing of this paper. C.B. and M.G. contributed to the development of this manuscript while on academic exchange in the School of Public Health, Griffith University.

\section{References}

1. Adamson A \& Cowburn G (1996) Community nutrition and dietetics: a survey of nutrition group members in 1995 . J Hum Nutr Diet 9, 339-348.

2. Hughes R (2004) Work practices of the community and public health nutrition workforce in Australia. Nutr Diet $6 \mathbf{1}$, $38-45$.

3. Hughes R (2005) A competency framework for public health nutrition workforce development. Australian Public Health Nutrition Academic Collaboration. http://www. aphnac.com/media/files/252.pdf (accessed October 2008).

4. Hughes R (2004) Competencies for effective public health nutrition practice: a developing consensus. Public Health Nutr 6, 839-847.

5. Hughes R (2007) Practice overview. In Public Health Nutrition: From Principles to Practice, pp. 265-272 [M Lawrence and A Worsley, editors]. St Leonards: Unwin \& Allen.

6. Labonte R, Woodard G, Chad K \& Laverack G (2002) Community capacity building: a parallel track for health promotion programs. Can J Public Health 93, 181-182.

7. World Health Organisation (1997) The Jakarta Declaration on leading health promotion into the 21st century. Health Promot Int 12, 261-264.

8. Shrimpton R (2002) Nutrition in communities. In Nutrition: A Foundation for Development. Geneva: ACC/SCN; available at http://acc.unsystem.org/scn (accessed July 2007).

9. Gillespie S, Mason J \& Martorell R. How Nutrition Improves. ACC/SCN State of the Art Series, Nutrition Policy Discussion Paper no. 15. Geneva: ACC/SCN.

10. Ismail S, Immink M, Mazar I \& Nantel G (2003) Community-based Food and Nutrition Programmes: What Makes Them Successful. Rome: FAO.

11. Hawe P, King L, Noort M, Gifford S \& Lloyd B (1998) Working invisibly: health workers talk about capacity building in health promotion. Health Promot Int 13, 285-295.

12. Horton D (2002) Planning, Implementing, and Evaluating Capacity Development. Briefing Paper no. 50. The Hague: International Service for National Agricultural Research.

13. Crisp B, Swerissen H \& Duckett S (2000) Four approaches to capacity building in health: consequences for measurement and accountability. Health Promot Int 15, 99-107.

14. Joffres C, Heath S, Farquharson J, Barkhouse K, Hood R, Latter C \& MacLean D (2004) Defining and operationalizing capacity for heart health promotion in Nova Scotia, Canada. Health Promot Int 19, 39-49.

15. Goodman R, Speers M, McLeroy K, Fawcett S, Kegler M, Parker E, Smith S, Sterling T \& Wallerstein N (1998) Identifying and defining the dimensions of community capacity to provide a basis for measurement. Health Educ Behav 25, 258-278.

16. Horton D, Alexaki A, Bennett-Lartey S et al. (2003) Evaluating Capacity Development: Experiences from Research and Development Organizations Around the World. The Netherlands: International Service for National Agricultural Research (ISNAR)/International Development Research Centre (IDRC).

17. United States Department Health and Human Services (1995) The Essential Public Health Services Work Group of the Core Public Health Functions Steering Committee.
Washington, DC: United States Department Health and Human Services.

18. National Public Health Partnership (2001) Public Health Practice in Australia Today - Core Functions. Melbourne: National Public Health Partnership.

19. Hughes R (2003) Public health nutrition workforce development: an intelligence based blue-print for Australia. PhD Thesis, Griffith University.

20. Strategic InterGovernmental Nutrition Alliance (2001) Eat Well Australia: An Agenda for Action for Public Health Nutrition 2000-2010. Canberra: Department of Health and Aged Care.

21. Trubswasser U, Branca F \& Tirado C (2006) Comparative Analysis of Nutrition Policies in the WHO European Region. Copenhagen: WHO Europe.

22. Lachat C, Van Camp J, De Henauw S, Matthys C, Larondell Y, Remaut-De Winter A-M \& Kolsteren P (2005) A concise overview of national nutrition action plans in the European Union Member States. Public Health Nutr 8, 266-274.

23. Gesellschaft fur Technische Zusammenarbeit (2003) Capacity Building Needs Assessment (CBNA) in the Regions (version 1.0) Module A. The Concept of Capacity Building and the Process of Assessing Capacity Building Needs. Jakarta: Deutsche Gesellschaft fur Technische Zusammenarbeit (GTZ); available at www.gtzsfdm.or.id/cb_cap_ assm.htm (accessed June 2007).

24. Brown L, Lafond A \& Macintyre K (2001) Measuring Capacity Building. Chapel Hill: University of North Carolina; available at http://pdf.usaid.gov/pdf_docs/ PNACM119.pdf (accessed June 2007)

25. LaFond A, Brown L \& Macintyre K (2002) Mapping capacity in the health sector: a conceptual framework. Int J Health Plann Manage 17, 3-22.

26. Hawe P, Noort M, King L \& Jordens C (1997) Multiplying health gains: the critical role of capacity-building within health promotion programs. Health Policy 39, 29-42.

27. Ewles L \& Simnett I (2003) Promoting Health: A Practical Guide, 5th ed. London: Bailliere Tindall.

28. Jonsson U (1988) A conceptual approach to understanding and explanation of hunger and malnutrition in society. In Hunger and Society. Cornell International Monograph Series no. 17. New York: Cornell University Program on International Nutrition.

29. Margetts B (2004) An overview of public health nutrition. In Public Health Nutrition, pp. 1-25 [M Gibney, B Margetts, J Kearney and L Arab, editors]. Oxford: Blackwell Publishing.

30. Barrett L, Plotnikoff R, Paine K \& Anderson D (2005) Development of measures of individual leadership for health promotion. Health Educ Behav 32, 195-207.

31. Millward L \& Bryan K (2005) Clinical leadership in health care: a position statement. Leadership Health Serv 18, xiii-Xxxv.

32. Hughes R (2003) A conceptual framework for intelligencebased public health nutrition workforce development. Public Health Nutr 6, 599-605.

33. Moyer A, Coristine M, MacLean L \& Meyer M (1999) A model for building collective capacity in community-based programs: the elderly in Need Project. Public Health Nurs 16, 205-214.

34. Campbell C \& Jovchelovitch S (2000) Health, community and development: towards a social psychology of participation. J Commun Appl Soc Psychol 10, 255-270.

35. World Health Organisation (1997) The Jakarta Declaration on leading health promotion into the 21 st century. Health Promot Int 12, 261-264.

36. Bush R (1997) Can we achieve sustainable reductions in harm in local communities? Drug Alcohol Rev 16, 109-111.

37. Laverack G (2001) An identification and interpretation of the organizational aspects of community empowerment. Community Dev J 36, 134-145. 
38. Shirlow P \& Murtagh B (2004) Capacity-building, representation and intracommunity conflict. Urban Stud $\mathbf{4 1}$, 57-70.

39. Chaskin R, Brown P, Venkatesh S \& Vidal A (2001) Building Community Capacity. New York: Aldine De Gruyter.

40. Jelinek M (1979) Institutionalising Innovation. A Study of Organisational Learning Systems. New York: Praeger.

41. Yeatman H \& Nove T (2002) Reorienting health services with capacity building: a case study of the Core Skills in Health Promotion Project. Health Promot Int 17, 341-350.

42. Hughes R (2005) A socio-ecological analysis of the determinants of national public health nutrition workforce capacity: Australia as a case study. Fam Community Health 29, 55-67.

43. Hughes R (2007) Introduction to public health nutrition practice. In Public Health Nutrition: From Principles to Practice [M Lawrence and A Worsley, editors]. Crows Nest: Allen \& Unwin.

44. Hughes R (2004) Work practices of the community and public health nutrition workforce in Australia. Nutr Diet 61, 38-45.
45. Kerzner H (2003) Project Management: A Systems Approach to Planning, Scheduling, and Controlling, 8th ed. New Jersey: John Wiley \& Sons.

46. Molleman G, Peters L, Hosman C, Kok G \& Oosterveld P (2006) Project quality rating by experts and practitioners: experience with Preffi $2 \cdot 0$ as a quality assessment instrument. Health Educ Res 21, 219-229.

47. Rifkin S (2003) A framework linking community empowerment and health equity: it is a matter of CHOICE. J Health Popul Nutr 21, 168-180.

48. Wescott G (2002) Partnerships for capacity building: community, governments and universities working together. Ocean Coastal Manage 45, 549-571.

49. Labonte R, Muhajarine N, Abonyi S, Woodard G, Jeffery B, Maslany B, McCubbin G \& Williams M (2002) An integrated exploration into the social and environmental determinants of health: the Saskatchewan Population Health and Evaluation Research Unit (SPHERU). Chronic Dis Can 23, $71-76$.

50. NSWHealth (2001) A Framework for Building Capacity to Improve Health. North Sydney: New South Wales Health Department. 